\title{
Reliability Verification of Unreinforced Masonry Wall
}

\author{
Mahdi Montazerolghaem ${ }^{1} \&$ Wolfram Jäger ${ }^{2}$ \\ ${ }^{1}$ University of Isfahan, Faculty of Engineering, Isfahan, Iran \\ ${ }^{2}$ Technical university of Dresden, Faculty of Architecture, Chair of structural design, Dresden, Germany \\ Correspondence: Mahdi Montazerolghaem, University of Isfahan, Faculty of Engineering, Isfahan, Iran. Tel: \\ 9891-3315-4228. E-mail: montazer9@gmail.com
}

Received: March 10, 2016

Accepted: March 27, 2016

Online Published: April 10, 2016

doi:10.5539/mas.v10n6p159

URL: http://dx.doi.org/10.5539/mas.v10n6p159

\begin{abstract}
Unreinforced masonry (URM) is known as sustainable building material and is on the top of worldwide building materials consumed in residential buildings. The reliability level of a designed URM shear walls (URMW) has major influence on safety and cost of masonry constructions. Assessing the reliability level of different URMW is the purpose of this paper.

The verification methods for combination of in-plane shear and compression according to the latest version of German National Annex of Eurocode 6are presented. The design models available in the code are rephrased and direct deterministic equations are introduced to predict the capacity. Limit State and Reliability Verification of URM Wall.

On this base, several limit state are established and reliability analysis using crude Monte Carlo method are run. The effect of uncertainty on assessed reliability is highlighted. The distinction between linear and non-linear application of partial safety factors are assessed. The result of reliability analysis, based on the available probabilistic information on material with uncertainty models for designed URMW is presented in the article.

The principal results are the actual reliability level found in the study regarding various masonry walls designed according to the latest German National Annex code DIN EN 1996-1-1 /NA: 2012-05 on different load situation. A review on the common target reliability index for structures according to different codes is done and the assessed reliability is compared with the target value.
\end{abstract}

Keywords: reliability, uncertainty, unreinforced masonry, shear wall, Eurocode 1996

\section{Introduction and Literature Review}

Perhaps, the main function of structural Unreinforced Masonry Wall (URMW) is carrying the axial load. The behavior of URMW under a pure axial force (centric load) has been and is the subject of many scientific assessments. However, in real boundary condition, the interconnection of other structural elements (like floor slab effect on wall) or external horizontal forces (like wind load) may cause some eccentricity, in-plane or out-of-plane of URMW.

Gardoni, Der Kiureghian, and Mosalam (2002) defined a "model" as a mathematical expression in relation to one or more quantities of interest. For instance the capacities of structural component, built by a set of finite basic variables $\left(x_{1}, x_{2}, \ldots, x_{n}\right)$, such as material property constants, member dimensions, and imposed boundary conditions. The main purpose of this model is to provide the means for predicting the quantities of interest for the given deterministic or random values of the basic variables. This definition is considered proper for the current study and the term "model" will be used for any mathematical relationship of shear capacity prediction of URMW.

Deterministic models are required not only for URMW design but also for probabilistic and Fuzzy assessment. Without deep understanding of structural behavior and having explicit deterministic models to predict the URMW load bearing capacity, the full probabilistic and fuzzy analysis will not lead to a credible outcome. Generally, in order to calculate the shear capacity of URMW, numerical methods and solver software are required.

Despite significant use of masonry constructions in relation to other building materials, the number of reliability studies on masonry structures are few. Moreover, the available studies on reliability of structural masonry are 
mostly limited to the basic models only (cf. Ellingwood (1980)). In recent years, the need for reliability studies on masonry is underlined. Nevertheless, most of the studies focus on masonry under axial forces.

An extensive study searching for a general methodology to obtain objective safety values for existing structures is run by Luc Schueremans (2001), where the found methodology is applied on unreinforced historical masonry structures under axial forces. L. Schueremans, van Gemert, and Maes (1999), adopted a combined model to evaluate the reliability of structural masonry elements through First Order Reliability Method (FORM) together with the response surface technique. For four material properties stochastic parameters in a non-linear finite element analysis of masonry shear wall is applied. Partial safety factors are omitted to allow these models to be used as the limit state formulation in a probabilistic approach.

Stewart and Lawrence (2002) have developed preliminary proof-of-concept techniques to estimate the structural reliability of masonry walls for vertical one-way bending and compression loading (see also Lawrence and Stewart (2008) and Stewart and Lawrence (2007)).

The studies run on masonry walls subject to in-plane or out of plane shear forces, which are the basic structural elements for the stiffening of a building against horizontal forces, are rare: Glowienka (2007) and Brehm (2011) developed some models to evaluate the structural reliability of masonry shear walls, Glowienka (2007) and Graubner and Glowienka (2008) run reliability analysis on masonry walls made of large size units and thin layer mortar.

SAKO report (SAKO, 1999) and the Expert Review on SAKO are interesting developments on load combination for Eurocode 1990 based on the reliability analysis. In the report, a conventional model is developed named as GENERIC model. The resistance part is material independent cross-section of a structural member; which can be replaced by any steel, concrete or masonry structural members. The model is loaded by three mutually independent actions: a permanent load, G, an imposed load, $\mathrm{Q}$ and climatic action, $\mathrm{W}$ (the characteristic values, $G_{k}, Q_{k}$ and $W_{k}$ denote the appropriate load effects, respectively). In the report the linear behavior for structural members and actions are assumed.

The economic design which is $R_{d}=E_{d}$ conducted. In case of generic structural member, the characteristic value $R_{k}$ of the resistance $\mathrm{R}$ may be defined as the $5 \%$ fractile of $\mathrm{R}$. The limit state model is presented as:

$$
g(X)=R-E=R-\theta_{E}\left(G_{0}+Q_{0}+W_{0}\right)
$$

where, $\theta$ is the uncertainty in the action effects. The study is run to determine the design value of load effect with three alternative combination rules provided in EN1990 (EN, 2009). The following single Eq. covers all the three combination rules provided in EN 1990:

$$
E_{d}=\xi \cdot \gamma_{G} \cdot G_{k}+\gamma_{Q} \cdot \psi_{Q} \cdot Q_{k}+\gamma_{W} \cdot \psi_{W} \cdot W_{k}
$$

The results reproduced by FORTRAN routines for Rackwitz-Fießler algorithm (Level II) and full-probabilistic method (Level III) run by these authors are illustrated in Figure 2 and Figure 3. In this study two load ratios $\chi=\left(Q_{k}+W_{k}\right) /\left(G_{k}+Q_{k}+W_{k}\right)$ and $\kappa=W_{k} / Q_{k}$ are assumed.

Despite all the efforts, little progress is made in reliability assessment of masonry structure and there is still enough room to study accurate evaluation of masonry structural reliability.

The focus of this study is mainly on the reliability of masonry walls subjected to in-plane shear forces. Here first, the target reliability in structural design is reviewed and next the procedure and required statistical data to build the specific limit state for URM shear wall is explained. The deterministic prediction models form German codes and Eurocode are taken for resistance part. The result of the recommended probabilistic uncertainty models are multiplied by the prediction models to obtain the realistic outcome. Adopting the recommended probabilistic action models as well as uncertainty models' different limit states are established and a comprehensive reliability analysis is conducted. Finally the comparative reliability level for URMW according to the different points of view is demonstrated. 


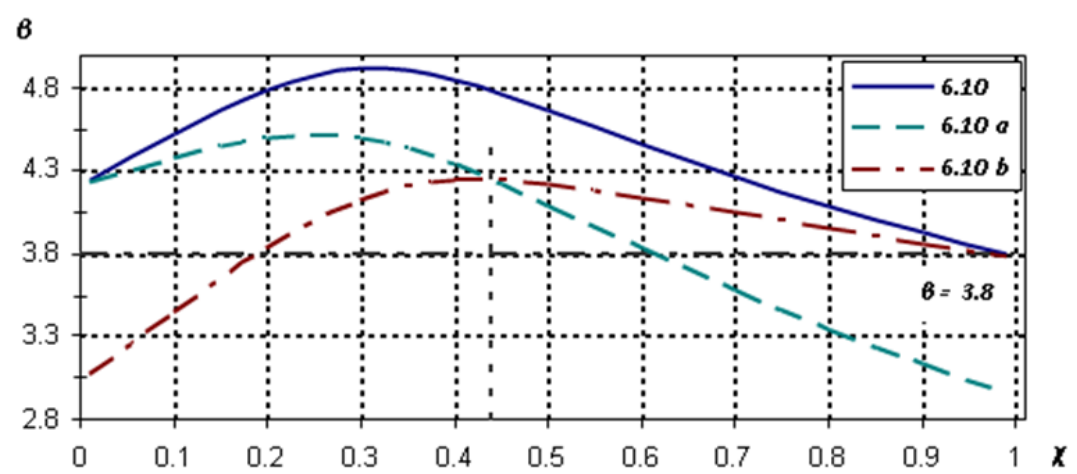

Figure 1. Reliability index $\beta$ versus $\chi$ assuming EN combination rules for $\mathrm{G}$, $\mathrm{Q}$ and $\mathrm{W}$; for $\kappa=0.75$, cov.R $=$ 0.10

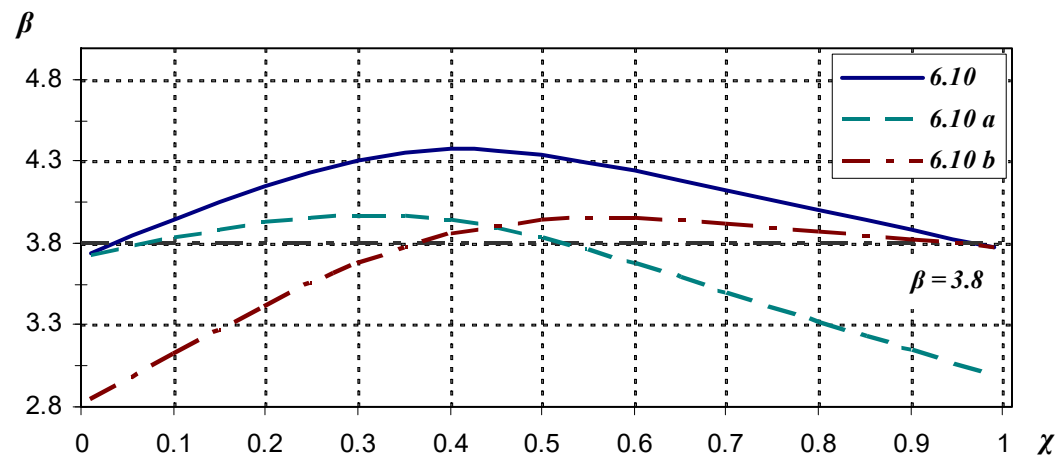

Figure 2. Reliability index $\beta$ versus $\chi$ assuming EN combination rules for $\mathrm{G}, \mathrm{Q}$ and $\mathrm{W}$; for $\kappa=0.75$, cov.R $=0.15$

\subsection{Structural Target Reliability Index}

Target reliability values balance the increasing cost and the existing levels of safety. In this context, different codes encompass detailed specifications. The proposed target reliability index in JCSS (2011) for ultimate limit states is tabulated in Table 1. The values in this table are obtained based on cost benefit analysis for the characteristic and representative but simple example structures and are compatible with calibration studies and statistical observations. The proposed target reliability index according to ISO 2394 (1998) is tabulated in Table 2.

Table 1. Tentative target reliability indexes, $\beta$ (and associated target failure rates), related to 50 years reference period and ultimate limit state JCSS (2011)

\begin{tabular}{lccc}
\hline & \multicolumn{3}{c}{ Reliability indexes, $\beta$, according to consequences of failure } \\
\cline { 2 - 4 } Relative cost of safety measure & minor & moderate & major \\
\hline A (large) & 1.7 & 2.0 & 2.6 \\
B (medium) & 2.6 & 3.2 & 3.5 \\
C (small) & 3.2 & 3.5 & 3.9 \\
\hline
\end{tabular}

Table 2. Tentative target reliability indexes, $\beta$ (and associated target failure rates), related to 50 years reference period and ultimate limit state JCSS (2011)

\begin{tabular}{lcccc}
\hline & \multicolumn{4}{c}{ Reliability indexes, $\beta$, according to consequences of failure } \\
\cline { 2 - 5 } Relative cost of safety measure & small & some & moderate & great \\
\hline high & 1 & 1.5 & 2.3 & 3.1 \\
moderate & 1.3 & 2.3 & 3.1 & 3.8 \\
low & 2.3 & 3.1 & 3.8 & 4.3 \\
\hline
\end{tabular}


Ravindra, Heaney, and Lind (1969) proposed a probabilistic code calibration method and set the target reliability to $\beta_{T}=2.71$ in order to determine the desired partial safety factor code in approximately the same safety level as what was available in the Canadian code then. Cornell (1969) found that value of $\beta_{T}=4.0$ is consistent with certain codes. Luc Schueremans (2001) reviewed some national and international codes for associated life time such as EC1: 1994; ISO 2394: 1998; ISO 12833: 1997; NBCC-part 4: 1990; NEN6700: 1997 and reported target reliability values as $\beta_{T}=3.8 ; 3.8 ; 3.8 ; 3.6 ; 3.5$, respectively. Stewart and Lawrence (2007) reported target reliability values for new Australian limit states codes as $\beta_{T}=3.5-4$. Vrouwenvelder (2002) recounted some developments towards full probabilistic design codes including target reliability and probabilistic models for different basic variables. Another recommendation according to the former German standard DIN 1055-100 (DIN, 2006) is $\beta_{T, 1}=4.7$ for the first year observation and $\beta_{T, 50}=3.8$ for an observation period of 50 years. In single cases, the values may be reduced to $\beta_{T}=3.2$.

Target values of reliability index in DIN EN 1990:2002 (DIN, 2011) for various design situations, and for reference periods of 1 year and 50 years, are tabulated in tables 3 and 4 . The values of $\beta_{T}$ in tables correspond to levels of safety for reliability class RC2 (see DIN EN 1990:2002 (DIN, 2011) Annex B) structural members.

Table 3. Target reliability indexes, $\beta$, related to life time reference period and ultimate limit state DIN EN 1990:2002 for Class RC2 structural members (DIN, 2011)

\begin{tabular}{lcc}
\hline & \multicolumn{2}{c}{ Reliability indexes, $\beta$, according to consequences of failure } \\
\cline { 2 - 3 } Relative cost of safety measure & small & some \\
\cline { 2 - 3 } & 4.7 & 3.8 \\
Ultimate & - & 1.5 to 3.8 \\
Fatigue & 2.9 & 1.5 \\
\hline Serviceability (irreversible) & depends on degree of inspectability, reparability and damage tolerance &
\end{tabular}

Table 4. Target reliability indexes, $\beta$, related to life time reference period and Reliability Class, DIN EN 1990:2002 table B2 (DIN, 2011)

\begin{tabular}{lcc}
\hline & \multicolumn{2}{c}{ Minimum reliability indexes acc. to Reliability Class } \\
\cline { 2 - 3 } Reliability Class & 1 year & 50 years \\
\hline RC1 & 5.2 & 4.3 \\
RC2 & 4.7 & 3.8 \\
RC3 & 4.2 & 3.3 \\
\hline
\end{tabular}

* Three reliability classes RC1, RC2 and RC3 may be associated with the three consequence classes CC1 (Low), CC2 (Medium) and CC3 (High). For more information see (DIN, 2011)

It should be noted that the partial factors given in EN 1990 up to EN 1999 generally lead to a structure design with a $\beta$ value greater than 3.8 for a 50 years reference period. In this study $\beta=3.8$ is chosen as the target value. However, in every design or verification, the target value is rarely met and nearly all the assessed reliability are either lower (not safe) or higher (not economy) than that of the target value. According to the authors opinion, an individual real number $\left(\beta_{T} \in \mathbb{R}\right)$ may not represent the structural target reliability adequately. Instead, introducing an interval such as $\left(\beta \in\left[\beta_{T, \min }, \beta_{T, \max }\right] \subset \mathbb{R}\right)$ may be more appropriate for this requirement.

\section{Limit State and Reliability Verification of URM Wall}

Mann and Müller (1978) proposed the theory of shear failure in masonry walls and later expanded their theory (Mann \& Müller, 1982), several principal failure criteria are counted:

- Friction failure of the bed joint,

- Tensile failure (cracking) of the units,

- Overturning of single unit,

- Compression failure of masonry (crashing).

Two other failures criteria are explicitly mentioned by other researchers (cf. Kranzler (2008)).

- Flexural (bending) failure of masonry,. 
- Shear compression failure of masonry,

In German National Annex of masonry design code DIN EN 1996-1-1/NA: 2012 (DIN, 2012), the main failure modes are the friction failure of bed joint and the diagonal tension failure in units. Moreover, depending on geometry of units and wall and properties of the mortar, two other failure modes namely shear compression failure and overturning of single unit are considered in this code. It should be noted that, the in-plane flexural failure is not explicitly expressed in the code, but it should be considered in design.

The design value of the shear resistance for friction failure and tensile failure of units is given by:

$$
V_{E D} \leq V_{R d l t}=\frac{f_{v k}}{\gamma_{M}} \cdot \frac{t}{c} \cdot l_{c a l}
$$

where, $c$ is shear stress distribution factor and is assigned as:

$$
\begin{array}{lcc}
1.0 & \text { for } & h / l \leq 1 \\
0.5(1+h / l) & \text { for } & 1<h / l<2 \\
1.5 & \text { for } & h / l \geq 2 ;
\end{array}
$$

and $l_{c a l}$ is the computational compressive length of wall. Under wind load action, $l_{c a l}$ is calculated through:

$$
l_{\text {cal }}=\min \left(\frac{9}{8} \cdot l_{w}, \frac{4}{3} \cdot l_{c, l i n}\right)
$$

in any other load actions, it is calculated through:

$$
l_{\text {cal }}=l_{c, \text { lin }}
$$

where, $l_{c, l i n}$ is the compressed length of wall. The Eq. (4) could be expanded in a mathematic manner to the following Eq. s:

$$
\begin{aligned}
& l_{\text {cal }}=1.125 . l_{w} \quad \text { for } \quad \frac{e}{l} \leq \frac{7}{32} \\
& l_{c a l}=2 .\left(l_{w}-2 . e\right) \quad \text { for } \quad \frac{7}{32}<\frac{e}{l} \leq \frac{1}{2}
\end{aligned}
$$

In contrast with $l_{c, l i n}$ in Eurocode 6, which defines the border of cracked and un-cracked state, in $l_{c a l}$ no physical character is of concern. The computed shear capacity of masonry wall up to $30 \%$ mathematically is enlarged; in other word, this is an implicit reduction of safety margin.

\subsection{Shear Friction and Tensile Failure due to EC6/NA: 2012-05}

In EN 1996-1-1/NA (DIN, 2012), the characteristic shear strength of masonry $\left(f_{v k}\right)$ for in-plane shear when meets the requirements of mortar joint may be taken from the minimum of Eqs. (8) and (9). The Eq. (8) determines the friction failure:

$$
f_{v, f r c}=\alpha \cdot f_{v k 0}+0.4 \cdot \sigma_{D}
$$

and in case of tensile failure of units the limit value is extracted from:

$$
f_{v, t e n}=0.45 \cdot f_{b t, c a l} \cdot \sqrt{1+\frac{\sigma_{D}}{f_{b t, c a l}}}
$$

where, $f_{v k 0}$ is the characteristic initial shear strength of masonry, that should be determined from tests or the table NA.11 in the code, $\alpha$ is a coefficient for initial shear strength of masonry, the head joint situation considered, $f_{b t, c a l}$ is the computational tensile strength of unit assumed as a fraction of unit compressive strength, $f_{b c}$, (from the table NA.3) and in the NA section "NDP zu 3.6.2 (3)" it is assumed as:

$f_{b t, c a l}=0.020 \cdot f_{b c}$ for hollow concrete blocks,

$f_{b t, c a l}=0.026 \cdot f_{b c}$ for vertically perforated clay bricks with finger holes or grippers,

$f_{b t, c a l}=0.032 \cdot f_{b c}$ for solid blocks without finger holes or grippers,

$f_{b t, c a l}=\frac{0.082}{1.25} \cdot \frac{1}{0.7+\left(\frac{f_{b c}}{b c}\right)^{0.5}} \cdot f_{b c}$ for AAC blocks with $L \geq 498 \mathrm{~mm}$ and $H \geq 248 \mathrm{~mm}$,

and $f_{b c}$ is the calculated mean compressive strength.

The direct shear capacity regarding to the friction criteria for economic design, $V_{E D}=V_{R d}$, could be derived. 
Eqs. (8) and (4) are implemented in Eq. (3) and the explicit mathematical Eq. to calculate the shear capacity in semi format for an interval of $7 / 32 \leq e / l \leq 1 / 2$, is proposed as follows:

$$
V_{R d, f r c, 3}=\frac{1.5 \cdot \cdot \cdot f_{v k 0}+0.4 \cdot n \cdot f_{k}}{0.75 \cdot c \cdot \gamma_{M}+\frac{3}{n} \cdot \frac{\alpha \cdot f_{v k 0}}{f_{k}} \cdot \frac{h_{W}}{l_{w}}} \cdot t \cdot l_{w}
$$

Analogues to friction, the direct formulation for tensile failure of units is computed according to EC6/NA: 2012-05.

\subsection{Shear Compression Failure due to EC6/NA: 2012-05}

The shear compression failure occurs when the compressive strength exceeds in the diagonal strut. The units' overlap is very important in this failure mode since it determines the angle of the diagonal compression. For element masonry with thin layer mortar in bed joint and overlap of $l_{o l} / h_{u}<0.4$ and high axial forces, the shear resistance at the base of the wall, in addition to detection by friction failure and tensile failure, is limited due to shear compression failure according to Eq (11).

$$
V_{R d}=\frac{1}{\gamma_{M} \cdot c} \cdot\left(t \cdot l_{c} \cdot f_{k}-\gamma_{M} \cdot N_{E D}\right) \cdot \frac{l_{o l}}{h_{u}}
$$

where, $\quad l_{c}=\left(l_{w}-2 \mathrm{e}\right)$. The direct relationship in semi format is:

$$
V_{R d}=\frac{\left(1-\gamma_{M} \cdot n\right) \cdot t \cdot l_{w} \cdot f_{k}}{\gamma_{M} \cdot c \cdot \frac{h_{u}}{l_{o l}}+\frac{\cdot}{n} \cdot \frac{h_{w}}{l_{w}}}
$$

\subsection{Overturning of Single Unit due to EC6/NA: 2012-05}

For element masonry with un-grouted head joints and aspect ratio of $h_{u}>l_{u}$ failure on single unit could occur at the opening of bed joint. Thus, in addition to the Eq. (3) (and if necessary according to (11)) shear resistance according to Eq. (13) is limited.

$$
V_{R d}=\frac{\frac{4}{3}}{\gamma_{M}} \cdot\left(\frac{1+\frac{h_{w}}{h_{u}}}{2 \cdot \frac{h_{w}}{h_{u}}}\right) \cdot \frac{l_{u}}{h_{u}} \cdot n \cdot t \cdot l_{w} \cdot f_{k}
$$

This failure mode depends only on dimensions. In order to consider material uncertainty, the correction factor $4 / 3=1.33$ is included.

The behaviour of different shear failure types for an exemplary clay brick wall according to the DIN EN 1996-1-1/NA (DIN, 2012) is illustrated in Fig 3.

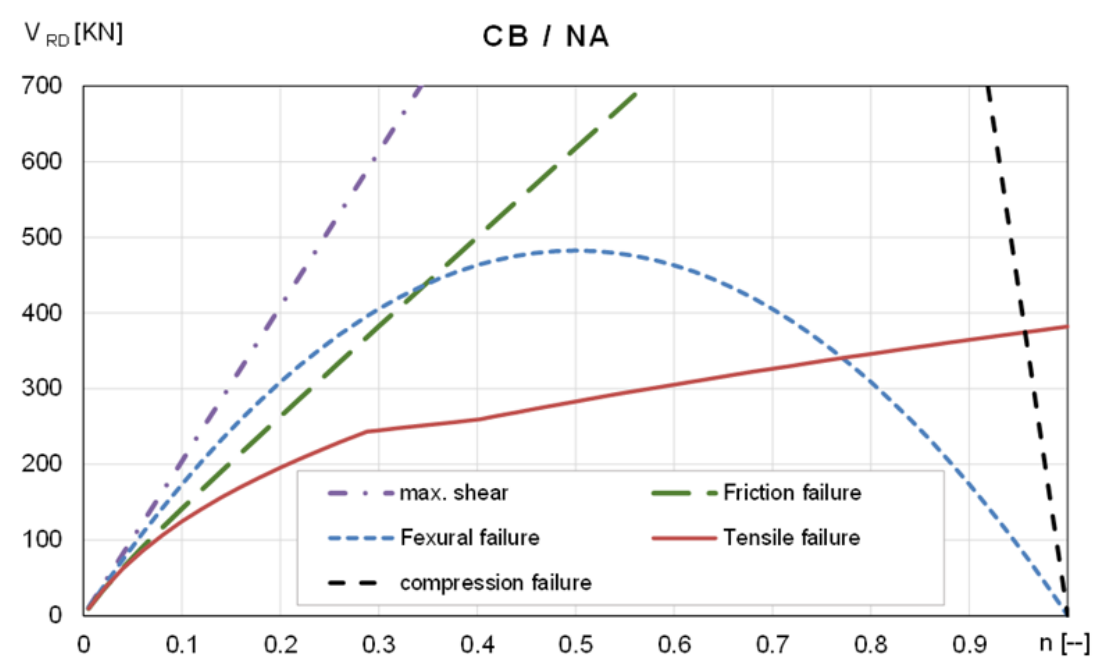

Figure 3. Performance of different shear failures criteria for an exemplary URMW

"Constructing a stochastic model of variables means establishing a representation of their variability by the best-suited probability density", according to Lemaire (2010). In the reliability analysis, information about statistical properties of the variables involved in the limit state function, Eqs. (14), for both the action and the resistance side are required. The resistance part in this study is obtained by prediction shear capacity due to 
different failure modes. The involved uncertainty in resistance, $\theta_{V R D}$ is the difference between observed capacity, $V_{o b s}$, from an experiment with applied vertical load,$N_{o b s}$ and predicted value from code, $V_{p r d}$, for the same vertical load. The information on all basic variables are summarized in Table 5.

$$
\mathrm{g}(\mathrm{x} \leq 0)=V_{R D} \cdot \theta_{R D}-V_{E D} \cdot \theta_{E D}
$$

In general limit state especially resistant part, $\left(V_{R D} \cdot \theta_{R D}\right)$, is combination of several basic variables each with different statistical distributions, therefore the outcome may be a "Mixture distribution" and may not represent a known statistical distribution.

\section{Reliability Level of Designed URMW}

The reliability level of designed unreinforced masonry shear wall according to DIN EN 1996-1-1/NA (DIN, 2012), corresponding to the Shear Compression Failure with respect to EC6/NA: 2012-05 the exemplary walls made of Clay Brick (CB), Calcium Silicate (CS) and Autoclaved Aerated Concrete (AAC) are assessed. In this section to consider uncertainty in resistance model, lognormal distribution is applied. Different software packages are available for reliability analysis. In this study, in order to calculate the failure probability, several subroutines in MATLAB are written using crude Monte Carlo method. Among the researchers it is accepted that the increasing the number of trails $(n \rightarrow \infty)$ will improve the accuracy of probability of failure. However, it is observed that the number of trails has significant influence on the consumed time.

\subsection{Effect of Non-Linear Partial Factor on this Model}

The deterministic performance of shear wall and the probabilistic behaviour are illustrated in Fig. 4. In this figure, $V R d\left(\gamma_{M}=1\right)$ represents the deterministic behaviour of URMW over the possible normal load interval $\left(0<n_{E D}<1\right) ; V R$ (randoms) is obtained by introducing the random values of basic variables into the same deterministic model. One of the interesting aspect here is the influence of uncertainty model, $\theta_{V R}$, which will shift the $V R$ (randoms) to new position of $V R * \theta_{V R}$. Meanwhile, $\theta_{V R}$ changes the scatter of predicted capacity. Ideally, each dot corresponds to the capacity of a real URMW for certain normal load $\left(n_{E D}(i)\right)$. The curve $\operatorname{VED}\left(\gamma_{M}=1.5\right)$ represents the deterministic design procedure by implementing $\gamma_{M}=1.5$ in the deterministic model. The curve $V E_{\text {mean }}$ identifies the wind mean value. Finally, the red cross marks signify the product of random wind load and random wind uncertainty, $V E_{m} * \theta_{V E}$.

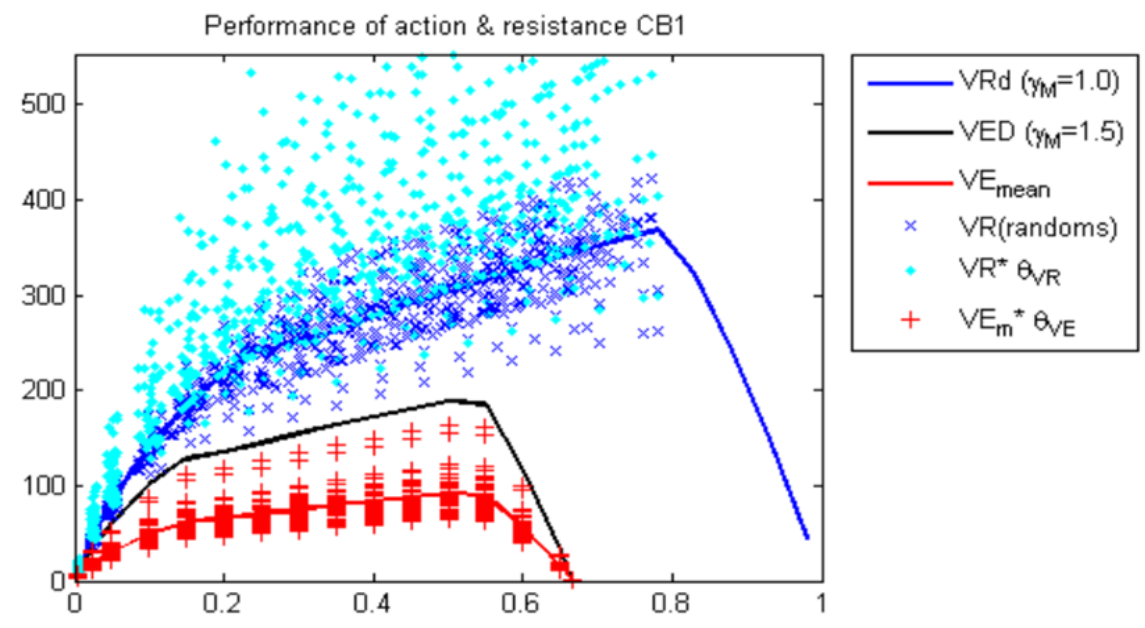

Figure 4. Deterministic and random performance of clay brick URMW designed due to DIN EN1996-1-1/ NA

Another intriguing feature is the graphical appearance of non-linear effect of partial factor in the model. As observed, applying partial factor in a linear manner, (e.g. applying $\gamma_{W}$ for mapping the design curve to wind load curve), only decrease the values in direction of y-axis. On the contrary applying partial factor in a non-linear method, will shift both coordinates of the original curve. As a result, for the case of URMW verification, applying $\gamma_{M}$ in deterministic model will shrink the possible normal load interval to $0<n_{E D}<$ $1 / \gamma_{M} \cong 0.67$.

Another consequence is misrepresentation of the designed structure behavior. Consider that the CB 1 wall needs to be verified for normal load of $\mathrm{n}=0.6$. For the real URMW, $\mathrm{n}$ is acting favorably and the capacity is increasing 
according to diagonal tensile curve while, the design and the wind load curves show that the $\mathrm{n}$ is acting un-favorably and the capacity is decreasing according to flexural curve (for $n>0.667$ with wind load); this means that this model is of higher resistance and lower action. Consequently, the number of failures drop sharply and will influence the reliability calculation. The assessed reliability curves are presented in Fig. 5. The information on assumed basic variables is tabulated in Table 5 .

Table 1. Statistical values assumed for basic variables in URM reliability evaluation (Montazerolghaem, 2015)

\begin{tabular}{lccccc}
\hline Basic variable & Symbol & Material & Distribution & Mean & Cov. \\
\hline Masonry compressive strength & $f_{k}$ & All & Lognormal & $\mu_{f}$ & $10 \%$ \\
unit calculated tensile strength & $f_{b t, c a l}$ & All & Lognormal & $\mu_{f b t, c a l}$ & $20 \%$ \\
Coefficient of friction & $\mu$ & All & Deterministic & 0.6 & -- \\
Initial shear strength & $f_{v k 0}$ & All & Lognormal & $\mu_{f v 0}$ & $35 \%$ \\
Normal force & $N_{E D}$ & All & Normal & $\mu_{n}$ & $10 \%$ \\
Wind load & $V_{E}$ & All & Gumbel & $\mu_{V E}$ & $20 \%$ \\
Uncertainty of wind load & $\theta_{V E}$ & All & Lognormal & 1 & $10 \%$ \\
Uncertainty of Shear resistance & $\theta_{V R}$ & AAC & Lognormal & 0.9367 & $24.2 \%$ \\
Uncertainty of Shear resistance & $\theta_{V R}$ & CB & Lognormal & 1.266 & $18 \%$ \\
Uncertainty of Shear resistance & $\theta_{V R}$ & CS & Lognormal & 1.0297 & $21.2 \%$ \\
\hline
\end{tabular}

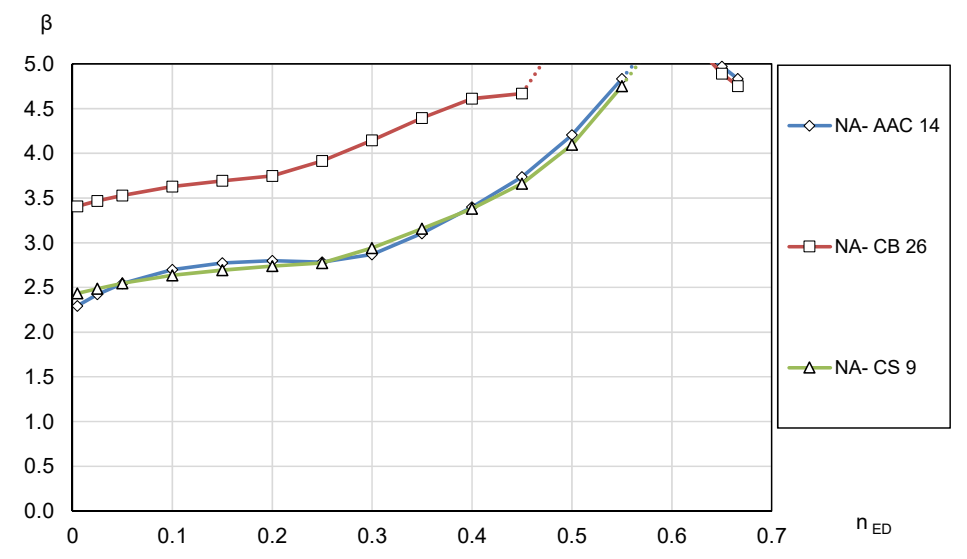

Figure 5. Reliability of cantilever URMW ( $\psi=1)$ designed according to DIN EN1996-1-1/ NA

\subsection{Applying the Partial Factor in Linear Manner in the Model}

A linear approximation method that may be used as an alternative case for a non-linear problem is illustrated in Fig 6. In this method, a linear projection of $\gamma_{M} \cdot V E D$ is applied to determine the resistance model. The curve $\gamma_{M} * V E D$ represents the deterministic approximate resistance model (black line) and the blue dots represent the random behaviour. The procedure to obtain wind load is the same as previous section. The evaluated reliability level is presented in Fig 7. The advantage here is that the resistance model and action model are in harmony in their performance. However, the linear projection does not match exactly with the real deterministic curve, which in general would lead to higher assessed reliability. Meanwhile, in case of flexural failure (last section of the curve), the resistance drops sharply (with a quadratic $n$ ). Thus, the loss of resistance is much higher than reduction in action, that leads to a sharp fall down in the assessed reliability curve's. 


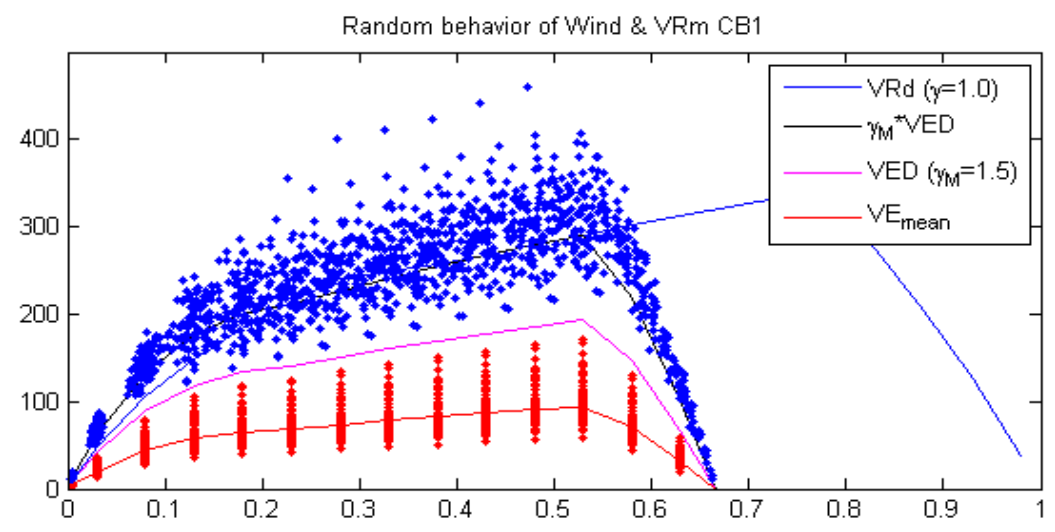

Figure 6. Deterministic and approximate random performance of URMW designed due to DIN EN1996-1-1/ NA, test No. CB 1

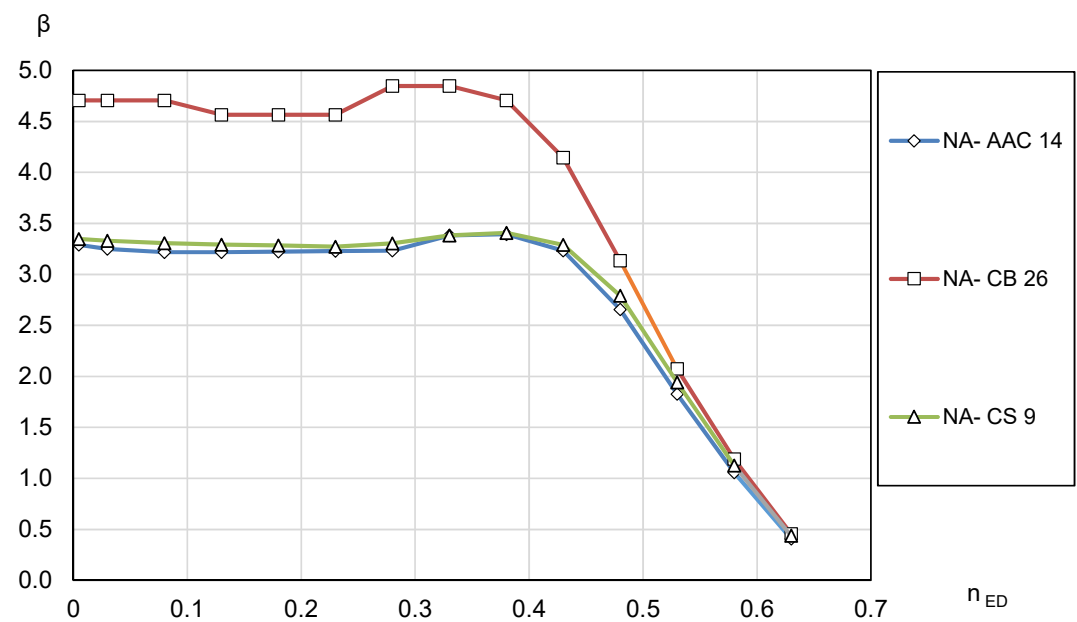

Figure 7. Reliability of cantilever URMW ( $\psi=1)$ designed due to DIN EN1996-1-1/ NA, approximate method 1

\subsection{Effect of Model Uncertainties on Reliability Assessments}

The reliability behaviour of the previous masonry shear walls based on the best-fitted uncertainty distribution of the refined database (Montazerolghaem \& Jäger, 2015) are evaluated. The following table contains the assumed basic variables for the resistance uncertainty model. The other basic variables and procedures are taken from previous section.

Table 6. Statistical values assumed for basic variables in URM reliability evaluation (Montazerolghaem, 2015)

\begin{tabular}{lcccc}
\hline Basic variable & Material & Distribution & Mean & Cov. \\
\hline Uncertainty of Shear resistance & AAC & Weibull(3P) & 0.9331 & $21.6 \%$ \\
Uncertainty of Shear resistance & CB & Gumbel min & 1.24 & $17.2 \%$ \\
Uncertainty of Shear resistance & CS & Weibull & 1.097 & $14.2 \%$ \\
\hline
\end{tabular}

The uncertainty model influences on the evaluated reliability considerably. In case of AAC, the uncertainty models are almost the same; therefore, the evaluated reliability remain unaffected, Fig. 8. In case of CS, the coefficient of variation is reduced; thus higher reliability is expected. This effect is obvious in evaluated reliability of CS in Fig. 9. In case of $\mathrm{CB}$, the type of uncertainty distribution changes. The lognormal distribution (with $\mu>1$ ) has an increasing right tail (positive skewness), in contrast, the Gumbel-min holds a decreasing left tail (negative skewness). The effect of model uncertainties on Reliability of URMW with CB is illustrated in Fig. 10. 


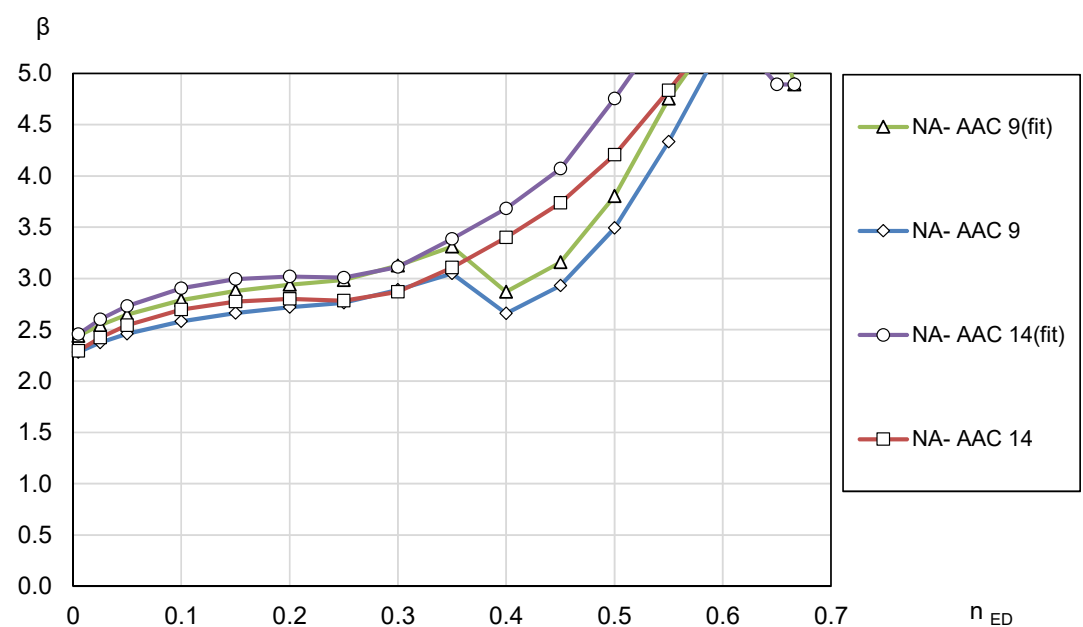

Figure 8 . The effect of model uncertainties on reliability of URMW with AAC

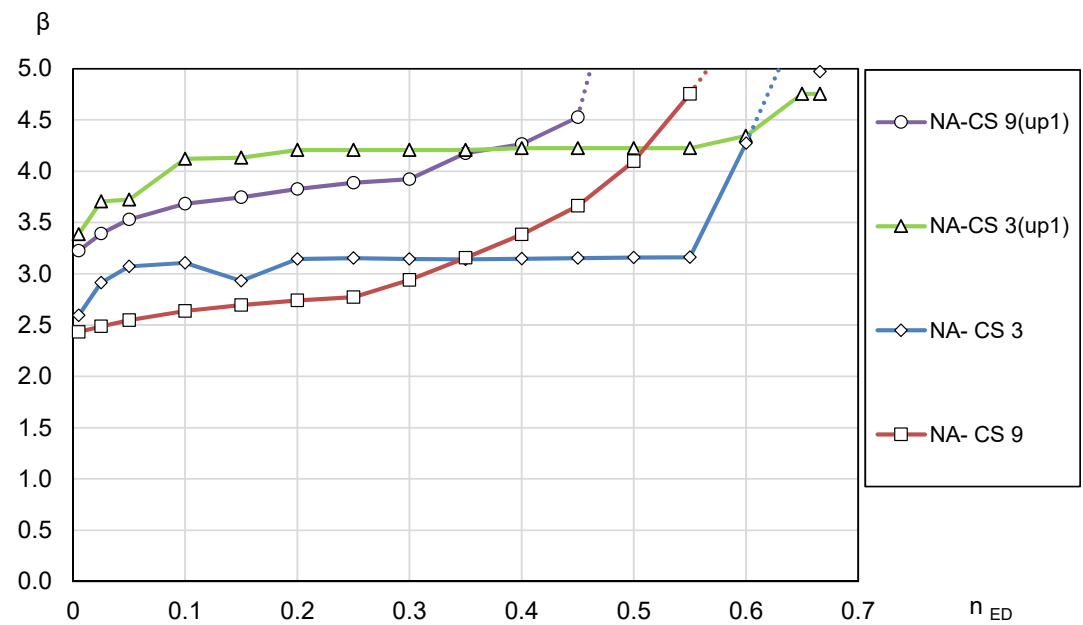

Figure 9. The effect of model uncertainties on reliability of URMW with CS

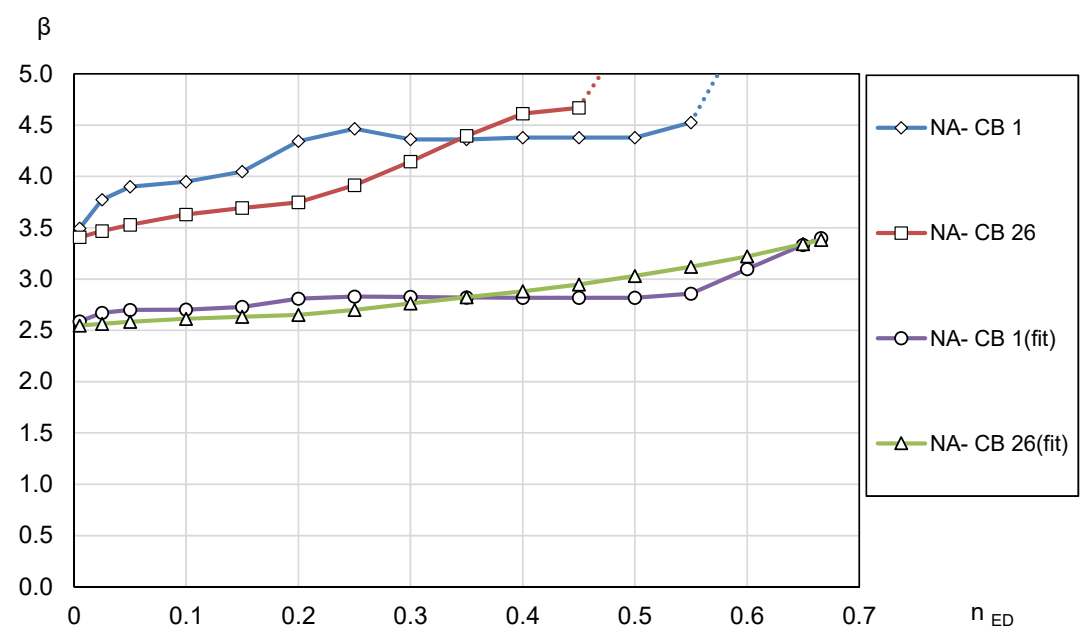

Figure 10. The effect of model uncertainties on reliability of URMW with CB 


\section{Conclusion}

The effect of random variation in data, which is named aleatory uncertainty, is studied. It is found that the model adopted to describe (aleatory) uncertainty has significant influence on the reliability level of URM wall. For the case of AAC the reliability level remain almost the same, but in case of CS, updating the uncertainty model increase the reliability level while for the case of CB it has adverse effect. Unfortunately, in many engineering problems (e.g. masonry structural elements) sufficient information does not exist to establish probabilistic model The verification models, especially in full probabilistic analysis can produce inaccurate output; thus, in order to select the appropriate uncertainty model extreme caution should be paid.

The effect of linear and/or non-linear implementation of partial factors is studied as well. Although, different deterministic verification methods may not provide significant difference in the outcomes, but this effect is obvious in a reliability analysis.

Finally, the reliability of different unreinforced masonry walls based on a full probabilistic analysis, according to current German national Annex of EC6 is assessed.

\section{References}

Brehm, E. (2011). Reliability of Unreinforced Masonry Bracing Walls -Probabilistic Approach and Optimized Target Values. (PhD), TU Darmstadt, Darmstadt. Retrieved from http://tuprints.ulb.tu-darmstadt.de/3142/

Cornell, C. A. (1969). Structural safety specifications based on second-moment reliability analysis. Paper presented at the IABSE reports of the working commissions, London. Retrieved from http://retro.seals.ch

DIN. (2006). Einwirkungen auf Tragwerke; Teil 100: Grundlagen der Tragwerksplanung, Sicherheitskonzept und Bemessungsregeln Part 100: Basis of design, safety concept and design rules (pp. 39). Berlin: DIN Deutsches Institut für Normung.

DIN. (2011). Eurocode: Grundlagen der Tragwerksplanung; Deutsche Fassung EN 1990: 2002 DIN EN 1990:2002 + A1:2005 + A1:2005/AC:2010 (pp. 87). Berlin: DIN Deutsches Institut für Normung.

DIN. (2012). Nationaler Anhang -National festgelegte Parameter -Eurocode 6 Teil 1-1: Allgemeine Regeln für bewehrtes und unbewehrtes Mauerwerk (pp. 68). Berlin: Deutsches Institut für Normung.

Ellingwood, B. (1980). Development of a probability based load criterion for American National Standard A58: Building code requirements for minimum design loads in buildings and other structures (Vol. 577): US Department of Commerce, National Bureau of Standards.

EN. (2009). Eurocode: Basis of structural design EN 1990:2002 (pp. 87). Berlin: DIN Deutsches Institut für Normung.

Gardoni, P., Der Kiureghian, A., \& Mosalam, K. M. (2002). Probabilistic capacity models and fragility estimates for reinforced concrete columns based on experimental observations. Journal of Engineering Mechanics, 128(10), 1024-1038. http://dx.doi.org/10.1061/(ASCE)0733-9399(2002)128:10(1024)

Glowienka, S. (2007). Zuverlässigkeit von Mauerwerkswänden aus großformatigen Steinen: probabilistische Analyse von großformatigem Mauerwerk aus Kalksandstein und Porenbeton mit Dünnbettvermörtelung. $(\mathrm{PhD})$, Technische Universität Darmstadt, Darmstadt. Retrieved from http://www.massivbau.tu-darmstadt.de Available from http://worldcat.org /z-wcorg/ database

Graubner, C. A., \& Glowienka, S. (2008). Probabilistisch fundierte Analyse von Tragreserven bei Mauerwerksgebäuden zur kostengünstigeren Bemessung von Druckgliedern und Biegebauteilen unter Eigenlast. In seriesEditor (Ed.), seriesTitle (1st ed., pp. 83). Stuttgart: FRaunhofer IRB-Verl.

Kranzler, T. (2008). Tragfähigkeit überwiegend horizontal beanspruchter Aussteifungsscheiben aus unbewehrtem Mauerwerk. (PhD), Technische Universität Darmstadt, Germany. Retrieved from http://www.massivbau.tu-darmstadt.de/massivbau/publikationen_fgm/dissertationen_4/index.de.jsp

Lawrence, S. J., \& Stewart, M. G. (2008). Reliability-based calibration of the capacity reduction factor for design of masonry in compression to AS3700 (pp. 46). Newcastle: University of Newcastle's Digital Repository.

Lemaire, M. (2010). Structural reliability (1st ed. Vol. 84). London: John Wiley \& Sons.

Mann, W., \& Müller, H. (1978). Schubtragfähigkeit von Mauerwerk. Mauerwerk-Kalender, 3, 35-65.

Mann, W., \& Müller, H. (1982). Failure of Shear-Stressed Masonry. An Enlarged Theory, Tests and Application to Shear Walls. Proceedings of the British Ceramic Society(30), 223-235. 
Montazerolghaem, M. (2015). Analysis of Unreinforced Masonry Structures with Uncertain Data. (PhD), Technische Universität Dresden, Germany. Retrieved from http://nbn-resolving.de/urn:nbn:de:bsz:14-qucosa-178418

Montazerolghaem, M., \& Jäger, W. (2015). Characterization of Uncertainty (Probabilistic Models) in Verification of Unreinforced Masonry Shear Wall. Mauerwerk European Journal of Masonry, 19(4), 287-297. http://dx.doi.org/10.1002/dama.201500670

Ravindra, M. K., Heaney, A. C., \& Lind, N. C. (1969). Probabilistic evaluation of safety factors. Paper presented at the IABSE reports of the working commissions, London. Retrieved from http://retro.seals.ch

SAKO. (1999). BASIS OF DESIGN OF STRUCTURES: Proposals for Modification of Partial Safety Factors in Eurocodes (pp. 90): The Nordic Committee on Building Regulations.

Schueremans, L. (2001). Probabilistic evaluation of structural unreinforced masonry. (PhD), KATHOLIEKE UNIVERSITEIT LEUVEN, Heverlee (Belgium). Retrieved from http://bwk.kuleuven.be/mat/publications/phdthesis/2001-schueremans-ph-d.pdf

Schueremans, L., van Gemert, D., \& Maes, M. (1999). EVALUATING THE RELIABILITY OF STRUCTURAL MASONRY ELEMENTS USING THE RESPONSE SURFACE TECHNIQUE. Paper presented at the 8th International Conference on Durability of Building Materials and Components, Vancouver, Canada. Retrieved from http://www.irbnet.de/daten/iconda/CIB2046.pdf

Stewart, M. G., \& Lawrence, S. (2002). Structural reliability of masonry walls in flexure. Masonry International, 15(2), 48-52.

Stewart, M. G., \& Lawrence, S. J. (2007). Model Error, Structural Reliability and Partial Safety Factors for Structural Masonry in Compression. Masonry International, 20(3), 107-116.

Vrouwenvelder, A. (2002). Developments towards full probabilistic design codes. Structural Safety, 24(2), 417-432. http://dx.doi.org/10.1016/S0167-4730(02)00035-8

\section{Copyrights}

Copyright for this article is retained by the author(s), with first publication rights granted to the journal.

This is an open-access article distributed under the terms and conditions of the Creative Commons Attribution license (http://creativecommons.org/licenses/by/3.0/). 